Jurnal Ilmiah Ibnu Sina, 6(2), Oktober 2021, 302-311

p-ISSN: 2502-647X; e-ISSN: 2503-1902

\title{
PENGARUH METODE PENGERINGAN TERHADAP KADAR SENYAWA BIOAKTIF DAN AKTIVITAS ANTIOKSIDAN PADA HERBA SURUHAN (Peperomia pellucida L.)
}

\author{
Dewi Puspita Apsari ${ }^{1 *}$, Muhammad Nanda Aprilianto ${ }^{1}$, Ni Luh Desyani ${ }^{1}$, \\ Ni Putu Widayanti ${ }^{2}$ \\ ${ }^{1}$ Program Studi Farmasi Klinis, Fakultas Ilmu-Ilmu Kesehatan, Universitas Bali \\ Internasional, Bali. \\ ${ }^{2}$ Program Studi Teknologi Laboratorium Medik, Fakultas Ilmu-Ilmu Kesehatan, \\ Universitas Bali Internasional, Bali. \\ *Email: dewipuspitaapsari@gmail.com
}

Artikel diterima: 18 Agustus 2021; Disetujui: 28 September 2021

DOI: https://doi.org/10.36387/jiis.v6i2.731

\begin{abstract}
ABSTRAK
Herba suruhan (Peperomia pellucida L.) telah digunakan secara global sebagai ramuan untuk tujuan medis dan terapeutik, sehingga banyak dibutuhkan untuk menyelidiki fitonutriennya. Variasi metode pengeringan dapat mempengaruhi kadar senyawa bioaktif dan aktivitas antioksidan, sehingga diperlukan strategi pengeringan yang sesuai dalam menghasilkan simplisia yang mengandung senyawa bioaktif dan aktivitas antioksidan yang tinggi. Atas dasar pertimbangan diatas, maka penelitian ini bertujuan untuk mengetahui pengaruh dari strategi variasi metode pengeringan (pengeringan sinar matahari langsung, pengeringan oven dan pengeringan kering angin) terhadap senyawa bioaktif dan aktivitas antioksidan dari herba suruhan. Ekstrak herba suruhan kemudian dianalisis flavonoid total, fenol total, tanin total, dan aktivitas antioksidannya. Hasil penelitian menunjukkan bahwa herba suruhan pengeringan oven menghasilkan potensi aktivitas antioksidan tertinggi yaitu 94,67 $\mu \mathrm{g} / \mathrm{ml}$ dengan flavonoid total 51,00 $\mathrm{mgQE} / \mathrm{g}$ ekstrak, fenol total 63,36 $\mathrm{mgGAE} / \mathrm{g}$ ekstrak, dan tanin total 41,89 mgTAE/g ekstrak. Dapat disimpulkan bahwa variasi metode pengeringan memiliki dampak yang signifikan $(\mathrm{p}<0,05)$ terhadap kadar bioaktif dan aktivitas antioksidan herba suruhan.
\end{abstract}

Kata kunci: Herba suruhan, Metode pengeringan, Kadar bioaktif, Aktivitas antioksidan, $\mathrm{IC}_{50}$

\begin{abstract}
Suruhan herb have been used globally as concoction for medical and therapeutic purposes, so that it is much needed to investigate their phytonutrients. The variations in drying methods can affect the levels of bioactive compounds and antioxidant activity, so an appropriate drying strategy is needed to produce simplicia that containing high bioactive compounds and antioxidant activity. Based on the considerations above, this study aimed to determine the effect of various
\end{abstract}


Jurnal Ilmiah Ibnu Sina, 6(2), Oktober 2021, 302-311

p-ISSN: 2502-647X; e-ISSN: 2503-1902

drying methods strategies (direct sunlight, oven drying and wind drying) on the bioactive compounds and antioxidant activity of the suruhan herb. The extract of suruhan herb were subsequently analyzed for total flavonoids, total phenols, total tannins, and their antioxidant activity. The results showed that oven-dried suruhan herb produced the highest potential antioxidant activity, that was $94.67 \mathrm{ppm}$ with total flavonoids $51.00 \mathrm{mgQE} / \mathrm{g}$ extract, total phenol $63.36 \mathrm{mgGAE} / \mathrm{g}$ extract, and total tannins $41.89 \mathrm{mgTAE} / \mathrm{g}$ extract. It can be concluded that the variety of drying strategy has a significant impact $(p<0.05)$ on the bioactive content and antioxidant activity of the suruhan herb

Keywords: Suruhan herb, Drying method, Bioactive content, Antioxidant activity, $I C_{50}$

\section{PENDAHULUAN}

Herba suruhan dengan nama latin Peperomia pellucida (L.) Kunth merupakan ramuan yang secara tradisional telah digunakan untuk menyembuhkan penyakit seperti antimikroba, antiprotozoal, antiinflamasi, analgesik, antiulcer, dan antioksidan (Majumder dkk, 2011). Herba suruhan telah terbukti mengandung senyawa flavonoid, fenol dan tanin yang berkontribusi terhadap aktivitas antioksidannya (Amarathunga dan kankanamge, 2017).

Kandungan senyawa bioaktif pada suatu tanaman dapat dipengaruhi oleh metode pengeringan (Utomo dkk, 2009). Pujiastuti dan Saputri (2019), melaporkan bahwa strategi pengeringan menyebabkan perbedaan yang bermakna terhadap aktivitas antioksidan pada buah parijoto
(Medinilla speciose). Hasil riset menyatakan bahwa metode pengeringan oven mempunyai aktivitas antioksidan tertinggi dengan $\mathrm{IC}_{50}$ sebesar 33,75 $\mu \mathrm{g} / \mathrm{ml}$. Perbedaan metode pengeringan akan mengakibatkan perbedaan kadar senyawa bioaktif dan aktivitas antioksidannya. Hal ini perlu diteliti, karena hingga saat ini belum ada yang melaporkan tentang dampak dari variasi pengeringan pada kadar senyawa bioaktif dan aktivitas antioksidan herba suruhan.

Variasi metode pengeringan seperti pengeringan sinar matahari langsung, diangin-anginkan maupun menggunakan oven memiliki kelebihan dan kekurangan yang dapat mempengaruhi senyawa bioaktif dan aktivitas antioksidan pada tanaman tertentu (Bernard dkk, 2014). Pengeringan menggunakan oven lebih 
Jurnal Ilmiah Ibnu Sina, 6(2), Oktober 2021, 302-311

p-ISSN: 2502-647X; e-ISSN: 2503-1902

efektif karena akan terjadi penurunan kadar air yang sangat besar pada simplisia dalam waktu singkat. Namun pemakaian suhu tinggi dapat menyebabkan peningkatan biaya produksi (Winangsih dan Parman, 2013). Sementara pengeringan dengan diangin-anginkan dianggap lebih murah serta kestabilan senyawa fitokimia dalam tanaman tetap terjaga namun tidak efisien dalam segi waktu (Winangsih dan Parman, 2013). Pengeringan dengan sinar matahari langsung juga dapat menyebabkan penurunan aktivitas antioksidan yang disebabkan oleh sinar ultraviolet (Winangsih dan Parman, 2013). Oleh karena itu dipelukannya strategi metode pengeringan yang tepat sehingga didapatkan simplisia yang mempunyai kadar senyawa bioaktif dan aktivitas antioksidan yang tinggi.

\section{METODE PENELITIAN}

\section{Bahan Tanaman}

Herba suruhan yang diperoleh dari Desa Angseri, Kecamatan Baturiti, Tabanan. Bali, merupakan tanaman yang digunakan dalam riset ini.

\section{Bahan Kimia dan Reagen}

Reagen Folin-Ciocalteu, standar asam galat, standar kuersetin, metanol, larutan $\mathrm{Na}_{2} \mathrm{CO}_{3}$, larutan $\mathrm{AlCl}_{3}, 2,2$ difenil-1-picylhydrazyl (DPPH), reagen Folin-Denis, kalium asetat, larutan asam tanat, etanol 96\%, dan aquabidestilata.

\section{Persiapan Sampel}

Sampel dibagi menjadi beberapa bagian yang sama dan diperlakukan dengan berbagai metode pengeringan seperti gambar 1 .

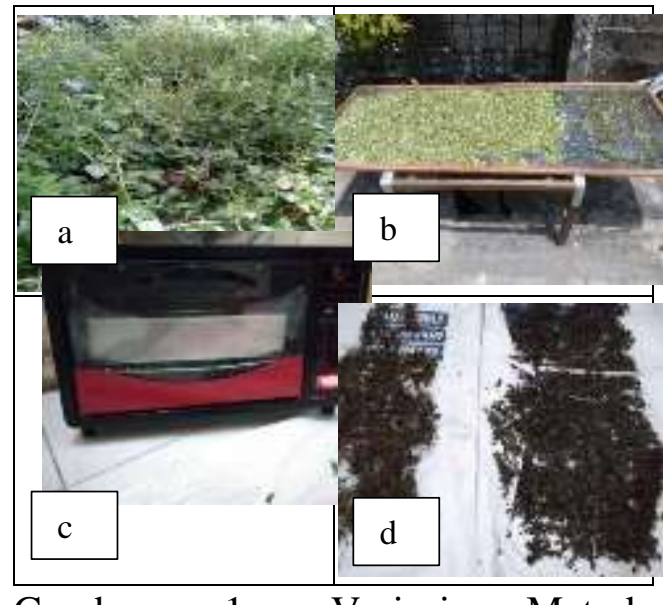

Gambar 1. Variasi Metode Pengeringan Herba Suruhan. (a) Herba suruhan; (b) Metode sinar matahari langsung; (c) Metode oven; (d) Metode diangin-anginkan.

$$
\text { Pengeringan matahari }
$$

langsung dilakukan selama 5 hari, pengeringan oven pada suhu $40^{\circ} \mathrm{C}$ selama 8 jam dan pengeringan diangin-anginkan selama 20 hari. Sampel kering yang didapat di 
Jurnal Ilmiah Ibnu Sina, 6(2), Oktober 2021, 302-311

p-ISSN: 2502-647X; e-ISSN: 2503-1902

haluskan menjadi bubuk dengan blender dan diayak menggunakan ayakan 60 mesh, kemudian bubuk herba suruhan dilakukan proses ekstraksi. Masing-masing serbuk herba suruhan sebanyak 500 gram dilarutkan ke dalam pelarut etanol $70 \%$ sebanyak $2,500 \mathrm{~mL}$ dengan rasio 1:5 (b/v) dan didiamkan selama $3 \times 24$ jam, kemudian disaring sehingga didapatkan filtrat I. Kemudian ditambahkan pelarut etanol $70 \%$ kembali sebanyak $1.250 \mathrm{~mL}$ ke dalam toples kaca dan didiamkan selama $3 \times 24$ jam, kemudian disaring sehingga didapatkan filtrat II. Filtrat I dan filtrat II digabung pada satu wadah, kemudian filtrat dilakukan proses pemekatan dengan rotating evaporator pada temperatur $40^{\circ} \mathrm{C}$ sampai mendapatkan ekstrak yang kental.

\section{Penetapan Kadar Flavonoid Total}

Ekstrak herba suruhan ditimbang $0,020 \mathrm{~g}, \quad$ kemudian ditambah $10 \mathrm{~mL}$ etanol 96\%, lalu aduk sampai larut. Larutan diambil $500 \mu \mathrm{L}$, direaksikan dengan etanol 96\% sebanyak $1,5 \mathrm{~mL}$, aluminium klorida $10 \%$ sebanyak $100 \mu \mathrm{L}$, aluminium asetat $1 \mathrm{M}$ sebanyak $100 \mu \mathrm{L}$ dan aquadest 2,8 mL, kemudian diamkan 30 menit. Serapannya ditentukan pada $\lambda$ maks $431 \quad \mathrm{~nm}$ dengan spektrofotometer UV-Vis. Serapan blanko diukur dengan prosedur yang sama, tanpa ditambahkan larutan uji. Sampel diukur sebanyak 3 kali replikasi.

\section{Prosedur Penentuan Fenolik Total}

Ekstrak herba suruhan ditimbang 0,010 g, kemudian ditambahkan etanol 96\% sebanyak $10 \mathrm{~mL}$, lalu aduk sampai larut. Larutan diambil $500 \mu \mathrm{L}$, ditambahkan dengan 5,0 mL FolinCiocalteu (dalam 7,5 mL air), dikocok dan didiamkan selama 5-10 menit. Kemudian ditambahkan $\mathrm{NaOH} 1 \%$ 4,0 $\mathrm{mL}$, dikocok dan didiamkan selama 1 jam pada temperatur ruang. Kemudian diukur serapannya pada $\lambda$ maks 735 $\mathrm{nm}$. Serapan blanko diukur dengan prosedur yang sama, tanpa penambahan larutan uji. Sampel diukur sebanyak 3 kali replikasi.

\section{Penetapan Kadar Tanin}

Ekstrak herba suruhan ditimbang $0,020 \mathrm{~g}, \quad$ kemudian dilarutkan dengan etanol $96 \%$ sebanyak $10 \mathrm{~mL}$. Larutan diambil $1000 \mu \mathrm{L}$, ditambahkan Folin denis 500 $\mu \mathrm{L}$ dan aquabidestilata sebanyak 7,5 
Jurnal Ilmiah Ibnu Sina, 6(2), Oktober 2021, 302-311

p-ISSN: 2502-647X; e-ISSN: 2503-1902

$\mathrm{mL}$, dikocok dan didiamkan selama 5 menit, lalu tambahkan1 $\mathrm{mL}$ larutan $\mathrm{Na}_{2} \mathrm{CO}_{3}$ jenuh, selanjutnya di vortex dan didiamkan selama 15 menit. Kemudian diukur serapannya pada $\lambda$ maks $652 \mathrm{~nm}$. Sampel diukur sebanyak 3 kali replikasi.

\section{Penentuan Aktivitas Peredaman Radikal DPPH}

a. Pengukuran

Antioksidan

\section{Aktivitas dengan}

\section{Spektrofotometer UV-Vis.}

Dipipet $2 \mathrm{~mL}$ sampel uji dengan varian konsentrasi 20;40;60;80; 100 $(\mu \mathrm{g} / \mathrm{ml})$ dan $2 \mathrm{~mL}$ larutan stok (40 $\mu \mathrm{g} / \mathrm{ml})$ DPPH. Kemudian masukkan dalam tabung reaksi. Selanjutnya dibuat larutan blanko dengan memipet $2 \mathrm{~mL}$ larutan stok DPPH dan metanol p.a. sebanyak $2 \mathrm{~mL}$ di vortex dan diamkan selama 30 menit pada temperatur ruang, lalu ukur absorbansinya pada $\lambda$ maks $516 \mathrm{~nm}$ dengan spektrofotometer UV-Vis. Pengukuran diulang sebanyak 3 kali replikasi.

\section{b. Penentuan Nilai IC $_{50}$ dan Potensi} Antioksidan

Masing-masing konsentrasi yang telah diukur absorbansinya akan didapatkan persentase peredaman menggunakan rumus:

$\%$ Inhibisi

$\frac{\text { Abs DPPH-Abs sampel }}{\text { Abs DPPH }} \times 100 \%$

Kemudian nilai yang diperoleh untuk setiap konsentrasi diplotkan untuk mendapatkan nilai $\mathrm{IC}_{50}$ ke dalam persamaan $\mathrm{y}=\mathrm{bx}+\mathrm{a}$, dimana $\mathrm{x}$ merupakan konsentrasi dan y adalah nilai redaman radikal (\%).

\section{Analisis Statistik}

Semua analisis dilakukan dalam tiga ulangan dan hasilnya dinyatakan sebagai rata-rata \pm standar deviasi. Analisis dilakukan menggunakan perangkat lunak SPSS yang didasarkan pada analisis varians (One Way ANOVA) diikuti oleh Tukey HSD (Honest Significant Difference) untuk menentukan perbedaan yang nyata terhadap perlakuan. $\mathrm{P}<0.05$ ditetapkan sebagai tingkat signifikan statistik.

\section{HASIL DAN PEMBAHASAN}

Pengujian fenol, flavonoid dan tanin total dari ekstrak herba suruhan pada berbagai variasi metode pengeringan memberikan perbedaan yang signifikan $\quad(p=0,000)$ sebagaimana yang ditunjukkan pada Tabel 1. Pada Tabel 1 terlihat metode 
Jurnal Ilmiah Ibnu Sina, 6(2), Oktober 2021, 302-311

p-ISSN: 2502-647X; e-ISSN: 2503-1902

pengeringan oven memiliki kadar fenol, flavonoid dan tanin total tertinggi dengan angka 63,36 $\mathrm{mgGAE} / \mathrm{g}, 51,00 \mathrm{mgQE} / \mathrm{g}$ dan 41,89 mgTAE/g secara berturut-turut. Hasil serupa seperti yang dilaporkan oleh Bernard dkk. (2014), dimana kadar fenolik dan flavonoid tertinggi pada kayu manis diperoleh pada pengeringan oven yaitu sebesar 0,238 $\mathrm{mgGAE} / \mathrm{g}$ dan 21,246 mgQE/g ekstrak secara berturut-turut. Widarta dan Wiadnyani (2019) juga menambahkan kadar tanin total tertinggi pada daun alpukat diperoleh pada pengeringan oven yaitu sebesar 2,48 mgTAE/g ekstrak. Hal ini dikarenakan pengeringan oven memastikan pengawetan senyawa bioaktif yang lebih baik (Samoticha dkk, 2010).

Metode pengeringan sinar matahari langsung memiliki kadar fenol, flavonoid dan tanin total terendah dengan angka 21,93 $\mathrm{mgGAE} / \mathrm{g}, 27,03 \mathrm{mgQE} / \mathrm{g}$ dan 22,79 mgQE/g secara berturut-turut. Sejalan dengan penelitian yang dilakukan oleh Bernard dkk. (2014), dimana kadar fenolik dan flavonoid terendah pada kayu manis diperoleh pada pengeringan sinar matahari langsung yaitu sebesar 0,120 $\mathrm{mgGAE} / \mathrm{g}$ dan 5,657 mgQE/g ekstrak ekstrak secara berturut-turut. Berbeda dengan penelitian yang dilakukan oleh Widarta dan Wiadnyani (2019) bahwa kadar tanin total terendah daun alpukat diperoleh pada pengeringan dianginanginkan yaitu sebesar 0,48 $\mathrm{mgTAE} / \mathrm{g}$ ekstrak. Penurunan kadar fenol dan tannin total disebabkan oleh terdegradasinya senyawa fenol pada simplisia, hal ini dikarenakan penjemuran yang intensif dan lama (Bernard dkk, 2014). Selain itu juga penurunan kadar flavonoid pada pengeringan sinar matahari terjadi karena adanya aktivasi enzim oksidatif yang menyebakan hilangnya kompleks senyawa flavonoid (Gumusay dkk, 2015).

Kemampuan peredaman radikal bebas DPPH yang diuji pada konsentrasi yang berbeda, menunjukkan bahwa masing-masing konsentrasi mengalami 
Jurnal Ilmiah Ibnu Sina, 6(2), Oktober 2021, 302-311

p-ISSN: 2502-647X; e-ISSN: 2503-1902

Tabel 1. Pengaruh metode pengeringan terhadap perolehan kadar fenolik total, flavonoid total, tanin todal, dan aktivitas antioksidan $\left(\mathrm{IC}_{50}\right)$ pada herba suruhan

\begin{tabular}{|c|c|c|c|c|c|}
\hline Perlakuan & $\begin{array}{c}\text { Fenolik Total } \\
\text { (mgGAE/g) }\end{array}$ & $\begin{array}{l}\text { Flavonoid } \\
\text { Total } \\
(\mathrm{mgQE} / \mathrm{g})\end{array}$ & $\begin{array}{l}\text { Tanin Total } \\
\text { (mgTAE/g) }\end{array}$ & $\mathrm{IC}_{50}(\mu \mathrm{g} / \mathrm{ml})$ & $\begin{array}{c}\text { P- } \\
\text { Value }\end{array}$ \\
\hline $\begin{array}{l}\text { Pengeringan } \\
\text { oven }\end{array}$ & $63,36 \pm 0,96^{\mathrm{a}}$ & $51,00 \pm 1,62^{\mathrm{a}}$ & $41,89 \pm 0,47^{\mathrm{a}}$ & $94,67 \pm 0,35^{\mathrm{a}}$ & \multirow{3}{*}{0,000} \\
\hline $\begin{array}{l}\text { Pengeringan } \\
\text { kering angin }\end{array}$ & $59,37 \pm 1,46^{\mathrm{b}}$ & $42,39 \pm 0,56^{\mathrm{b}}$ & $\begin{array}{l}37,32 \\
1,12^{\mathrm{b}}\end{array}$ & $\begin{array}{l}117,67 \\
1,41^{\mathrm{b}}\end{array}$ & \\
\hline $\begin{array}{l}\text { Pengeringan } \\
\text { sinar matahari } \\
\text { langsung }\end{array}$ & $21,93 \pm 1,96^{c}$ & $27,03 \pm 0,76^{c}$ & $22,79 \pm 0,45^{\mathrm{c}}$ & $\begin{array}{l}140,97 \\
0,61^{\mathrm{c}}\end{array}$ & \\
\hline
\end{tabular}

Keterangan: Rerata ( \pm standar deviasi) dengan superscript yang berbeda pada setiap kolom berbeda nyata menurut test uji Tukey HSD $(\mathrm{P}<0,05)$.

Perubahan nilai persentase peredaman seperti yang digambarkan oleh kurva hubungan antara konsentrasi larutan uji pada Gambar 1. Hasil pengujian aktivitas antioksidan dari ekstrak herba suruhan pada variasi metode pengeringan memberikan perbedaan yang signifikan $(\mathrm{p}<0,05)$ sebagaimana seperti yang ditunjukkan pada Tabel 1. Dapat diketahui pada Tabel 1 diatas bahwa metode pengeringan oven menghasilkan aktivitas antioksidan tertinggi dengan nilai $\mathrm{IC}_{50}$ sebesar $94,67 \mu \mathrm{g} / \mathrm{ml}$, sedangkan terendah diperoleh pada pengeringan sinar matahari langsung dengan nilai $\mathrm{IC}_{50}$ sebesar 140,97 $\mu \mathrm{g} / \mathrm{ml}$. Hasil serupa seperti yang dilaporkan oleh Pujiastuti dan Saputri. (2019) pada buah parijoto dimana nilai $\mathrm{IC}_{50}$ tertinggi diperoleh pada pengeringan oven yaitu sebesar 11,16 $\mu \mathrm{g} / \mathrm{ml}$, sedangkan terendah diperoleh pada pengeringan sinar matahari yaitu sebesar 164,19 $\mu \mathrm{g} / \mathrm{ml}$. Hal ini dikarenakan pengeringan oven dapat menghasilkan berat kering konstan, selain itu juga pengeringan oven membuat senyawa bioaktif yang lebih baik dan akibatnya aktivitas antioksidan yang lebih tinggi (Samoticha dkk, 2016).

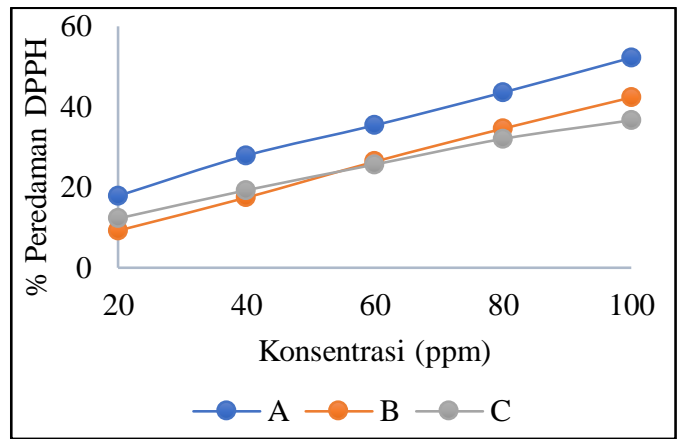

Gambar 1. Aktivitas antioksidan herba sirih cina diuji dengan metode DPPH. Hasil dinyatakan sebagai persentase $(\%)$ dari peredaman.

Keterangan: $\mathrm{A}=$ pengeringan oven, $\mathrm{B}=$ pengeringan kering angin, $\mathrm{C}=$ pengeringan sinar matahari langsung. 
Jurnal Ilmiah Ibnu Sina, 6(2), Oktober 2021, 302-311

p-ISSN: 2502-647X; e-ISSN: 2503-1902

Proses pengeringan diangin- sekunder pada simplisia seperti anginkan dengan waktu yang relatif flavonoid dan fenol (Winangsih dan lama pada temperatur ruang Parman, 2013). Seperti yang mengakibatkan penurunan kualitas diungkapkan oleh Chan dkk (2009), senyawa kimia pada simplisia.

Hasil serupa dilaporkan oleh Purwanti dkk, (2018), bahwa aktivitas antioksidan pada ekstrak daun pandan menurun seiring lamanya waktu pengeringan. Hal ini berkaitan dengan aktivitas air, pengeringan dengan kering angin menghasilkan kadar air lebih tinggi dibandingkan menggunakan suhu panas (Samoticha dkk, 2016). Menurut Garau dkk (2007), pengeringan dengan cara kering angin menunjukkan bahwa pada suhu ini tidak adanya peningkatan yang signifikan dalam laju pengeringan. Fenomena ini dikenal sebagai efek case-hardening, yang dapat diartikan sebagai efek yang dapat menghalangi pelepasan air dan memperlambat laju pengeringan.

Pengeringan menggunakan sinar matahari langsung menghasilkan aktivitas antioksidan terendah. Penurunan nilai aktivitas antioksidan dengan sinar matahari langsung terjadi karena sinar ultraviolet dari matahari dapat merusak senyawa metabolit proses pengeringan sinar matahari langsung menyebabkan penurunan aktivitas antioksidan lebih besar. Selama proses pengeringan dengan sinar matahari langsung, terjadinya aktivasi enzim oksidatif seperti peroksidase dan polifenoloksidase yang menyebabkan hilangnya kompleks fenol (Gumusay dkk, 2015).

\section{KESIMPULAN}

Tampak bahwa variasi metode pengeringan memiliki pengaruh yang signifikan pada kadar senyawa bioaktif dan aktivitas antioksidan pada ekstrak herba suruhan. Diantara metode pengeringan yang telah dilakukan, cara pengeringan oven merupakan metode pengeringan terbaik untuk mengasilkan flavonoid total, fenol total, tanin total dan aktivitas antioksidan tertinggi.

\section{UCAPAN TERIMAKASIH}

Terimakasih kepada seluruh pihak yang telah berkontribusi dalam penelitian ini, serta Program Studi 
Jurnal Ilmiah Ibnu Sina, 6(2), Oktober 2021, 302-311

p-ISSN: 2502-647X; e-ISSN: 2503-1902

Farmasi Klinis Universitas Bali

Internasional atas dukungan sarana dan prasarana sehingga selama pelaksanaan penelitian ini berjalan dengan baik.

\section{DAFTAR PUSTAKA}

Amarathunga, A.A.M.D.D.N. and Kankanamge, S.U., 2017. A review on pharmacognostic, phytochemical and ethnopharmacological findings of Peperomia pellucida (L.) Kunth: pepper elder. Int. Res. J. Pharm, 8(11), 16-23.

Bernard, D., Kwabena, A.I., Osei, O.D., Daniel, G.A., Elom, S.A., Sandra, A. 2014. The effect of different drying methods on the phytochemicals and radical scavenging activity of Ceylon Cinnamon (Cinnamomum zeylanicum) plant parts. European Journal of Medicinal Plants 4(11), 1324-1335.

Chan, E.W.C., Lim, Y.Y., Wong, S.K., Lim, K.K., Tan, S.P., Lianto, F.S. and Yong, M.Y., 2009. Effects of different drying methods on the antioxidant properties of leaves and tea of ginger species. Food chemistry, 113(1), 166-172.

Garau, M.C., Simal, S., Rossello, C. and Femenia, A., 2007. Effect of air-drying temperature on physico-chemical properties of dietary fibre and antioxidant capacity of orange (Citrus aurantium v. Canoneta) by- products. Food chemistry, 104(3), 1014-1024.

Gümüşay, Ö.A., Borazan, A.A., Ercal, N. and Demirkol, O., 2015. Drying effects on the antioxidant properties of tomatoes and ginger. Food chemistry, 173, 156-162.

Majumder, P., Abraham, P. and Satya, V., 2011. Ethno-medicinal, phytochemical and pharmacological review of an amazing medicinal herb Peperomia pellucida (L.) HBK. Res J Pharm Biol Chem Sci, 2(4), 358-64.

Pujiastuti, E. and Saputri, R.S., 2019. Pengaruh metode pengeringan terhadap aktivitas antioksidan ekstrak etanol. Cendekia Journal of Pharmacy, 3(1), 4452.

Purwanti, N.U., Yuliana, S. and Sari, N., 2018. Pengaruh Cara Pengeringan Simplisia Daun Pandan (Pandanus Amaryllifolius) Terhadap Aktivitas Penangkal. Jurnal Farmasi Medica/Pharmacy Medical Journal (PMJ), 1(2), 63-72

Samoticha, J., Wojdyło, A. and Lech, K., 2016. The influence of different the drying methods on chemical composition and antioxidant activity in chokeberries. LWT-Food Science and Technology, 66, 484-489.

Utomo, A.D., Rahayu, W.S. and Dhiani, B.A., 2009. Pengaruh beberapa metode pengeringan terhadap kadar flavonoid total herba sambiloto (Andrographis 
Jurnal Ilmiah Ibnu Sina, 6(2), Oktober 2021, 302-311

p-ISSN: 2502-647X; e-ISSN: 2503-1902

paniculata). PHARMACY:

Jurnal Farmasi Indonesia

(Pharmaceutical Journal of

Indonesia), 6(01), 1693-3591

Widarta, I.W.R. and Wiadnyani, A.A.I.S., 2019. Pengaruh Metode Pengeringan terhadap Aktivitas Antioksidan Daun
Alpukat. Jurnal Aplikasi Teknologi Pangan, 8(3), 80-85.

Winangsih, W. and Parman, S., 2013. Pengaruh metode pengeringan terhadap kualitas simplisia lempuyang wangi (Zingiber aromaticum L.). Anatomi Fisiologi, 21(1), 19-25 